\title{
Scenario Object Model Based On-Line Safety Analysis for Chemical Process
}

\author{
D. Gao, ${ }^{a^{*}}$ B. K. Zhang, ${ }^{a}$ X. Xu, ${ }^{\text {b }}$ and C. G. Wu ${ }^{a}$ \\ a College of Information Science and Technology, Beijing University of Chemical Technology, \\ Beijing, P.R. China \\ ${ }^{b}$ Beijing Digital Process Technology Co. Ltd., Beijing, P.R. China
}

This work is licensed under a Creative Commons Attribution 4.0

\begin{abstract}
\| Abstract
HAZOP (Hazard and Operability Analysis) is a method of safety analysis, which is widely used in chemical processes. The conventional methods for safety analysis consist of human based safety analysis and computer aid safety analysis. All of them are off-line and qualitative and it is difficult to carry out on-line safety analysis. Online safety analysis based on scenario object model was proposed for chemical processes. The scenario object model was built using ontology, by which the safety information can be transferred, reused and shared effectively. Deviation degree and qualitative trend were added to the model. Based on the model and new inference algorithm, on-line safety analysis can be implemented for chemical processes. Once a fault or abnormal event occurs, the causes can be traced and the consequences can be predicted. At the same time, semi-quantitative safety analysis is carried out. The resolution can be improved and it can help the operators handle the problems in time and effectively. The method was used for safety analysis of a reactor process and the effectiveness of the method was proved.
\end{abstract}

\section{\| Keywords}

Scenario object model, on-line, hazard analysis, HAZOP, qualitative trend

\section{Introduction}

HAZOP is one of the safety analysis methods based on system engineering. ${ }^{1}$ It is widely used in chemical processes for safety analysis in recent years in China. ${ }^{2-7}$ In addition, it is the most widely used safety analysis method. Howev$\mathrm{er}$, it is difficult to reuse and share the safety information in HAZOP. This problem needs to be solved. On the one hand, the results and records are usually missed and the results are difficult to research in HAZOP; on the other hand, it is very important and necessary to reuse and share the information. The information of safety analysis can be used in the full life cycle of a factory including stages of design, construction, production, maintenance of production equipment. At the same time, the information needs to be transferred between different units of factory and different teams. Non-standard information will cause huge costs of human resources and material resources.

The research on the reuse and share of safety analysis information has been carried out. The key problem of reuse and sharing of information is standardization of information. ISO-10303 and ISO-15926 are international standards about information on chemical processes. ${ }^{8,9}$ Some researchers have begun to research the standardization of HAZOP information. ${ }^{10-12}$ However, the models are too complex and difficult to use. Wu proposed a SOM (Scenario Object Model) based on ontology to realize the standardization of safety analysis information. The problems of information hiding and missing can be solved by the model. Then, based on the model, computer aid automat-

${ }^{*}$ Corresponding author: Gao Dong, Ph.D.

e-mail: gaodong@mail.buct.edu.cn ic safety analysis was proposed and developed. The safety analysis information can be transferred, reused and shared effectively. ${ }^{13-15}$

The problems of safety analysis information transfer reuse and sharing have been solved. However, the model needs to be improved for on-line safety analysis. The conventional safety analysis consists of human based safety analysis and computer aid safety analysis. All of them are carried out off-line and cannot be used for on-line safety analysis. If HAZOP can be carried out on-line, once a fault or abnormal event occurs, safety analysis can be done in time, the causes of fault can be found, the consequences can be predicted in time, and more serious accidents can be avoided. It is very useful for the safety of the chemical processes.

Some researchers have attempted on-line safety analysis by searching results in the database which were obtained by off-line safety analysis. ${ }^{16}$ Obviously, this method is unsatisfactory. Once a fault or abnormal event occurs which is not in the database, the on-line safety analysis cannot find causes and consequences.

A suitable expert system is needed for on-line safety analysis. Deep knowledge model such as SDG (Signed Directed Graph) or SOM can represent the relationship between causes and consequences. Deep knowledge model can reveal the rules of faults development and evolution. It is the mathematical expression of interactions of different units in the production. ${ }^{17}$

All the faults caused by deviation can be found by inference and calculation based on the deep knowledge model. The diagnosis completeness can be improved and the 
essential causes can be found using the deep knowledge model. ${ }^{18,19}$

In this article, the scenario object model based on-line safety analysis is proposed for chemical processes. Firstly, the scenario object model was extended and improved for on-line safety analysis. New definitions, rules and properties such as deviation degree and qualitative trend were introduced into the model. Then, based on the model, new inference algorithm was proposed for on-line safety analysis. Once a fault or abnormal event occurs, the causes can be traced and the consequences can be predicted. The resolution can be improved and can help the operators handle the problems in time and effectively.

\section{Improved scenario object model for on-line safety analysis}

The on-line safety analysis needs to carry out inference to find possible causes and predict possible consequences according to the current states of the system. The core issue is the model. The model used for on-line safety analysis should satisfy the following requirements:

(1) Complex relationship between variables in chemical process, the relationship between causes and consequences and the states of system in different conditions can be stored and represented by the model. (2) The elements and rules in the model should be improved to be suitable for on-line safety analysis. The analysis resolution should be improved. (3) The information should be transferred, reused and shared easily in the model.

The improved scenario object model is proposed to satisfy these requirements. New elements are added to the conventional scenario object model for on-line safety analysis. The structure of the model is shown in Fig. 1.
The model includes event and relationship. The event consists of middle event, cause, consequence and safety precaution. Compared with conventional scenario object model, deviation degree and qualitative trend are added to the model to improve the accuracy. At the same time, the relationship between events is extended by adding qualitative trend relationship to the model. On one hand, the new scenario object model has the advantage of the conventional scenario object model. The information can be easily transferred, reused and shared. On the other hand, new elements are added to improve the model for on-line safety analysis.

\subsection{Definitions of elements}

(1) Middle event. Middle event is used to describe the physical state or chemical state of a process such as temperature, pressure, level, flow etc. The states of the middle event are described by qualitative state, deviation degree, and qualitative trend.

Qualitative state is described by deviation and guide words. The state can be "positive deviation" ("+"), "negative deviation" ("-") or "normal" (" 0 "). For example, the state of a variable's temperature, which is higher than normal value, can be represented by "positive deviation". Besides qualitative state, deviation degree and qualitative trend are both used to describe the state of middle event.

Deviation degree represents the degree to which the event or variable exceeds its limits. It is calculated by Eq. (1).

$$
P=\left\{\begin{array}{l}
\frac{v-v_{\text {set }}}{v_{\text {max }}-v_{\text {set }}}, v \geq v_{\text {set }} \\
\frac{v-v_{\text {set }}}{v_{\text {min }}-v_{\text {set }}}, v<v_{\text {set }}
\end{array}\right.
$$

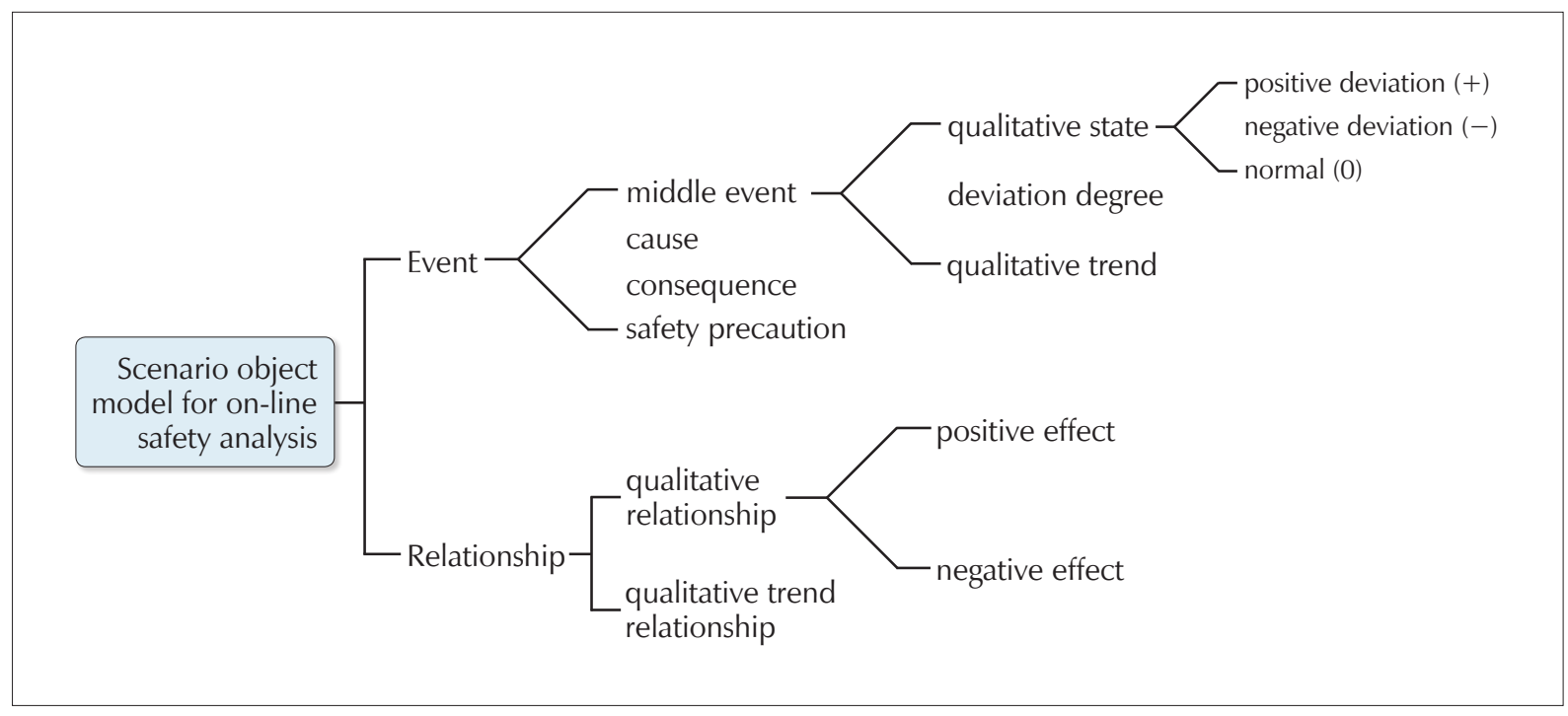

Fig. 1 - Elements of scenario object model for on-line safety analysis 
$P$ is deviation degree, $v$ is measured value, $v_{\text {set }}$ is set point, $v_{\max }$ is maximum value, $v_{\min }$ is minimum value. The deviation degree is between 0 and 1.

Qualitative trend represents the trend of the middle event. Compared with qualitative state and deviation degree, the qualitative trend can describe the state in more details. The qualitative trend is represented by six basic primitives. They are shown in Fig. 2.
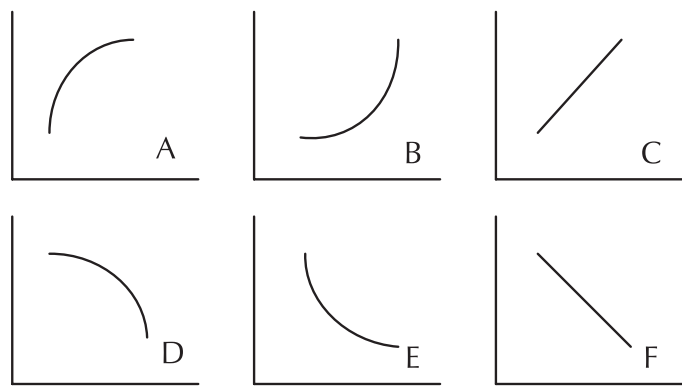

Fig. 2 - Basic qualitative trend primitives

The state of middle event is described by positive state ("positive deviation", "negative deviation" and "normal") in conventional scenario object model. The states of the middle event are described in three levels: qualitative state, deviation degree, and qualitative trend in the new scenario object model. The accuracy of model can be improved.

(2) Cause. Cause is the reason of an accident happening, including device failure, device fault, and wrong operation. For example, control system failure, pressure regulator failure, instrument failure, value fault, etc.

(3) Consequence. Consequence is the result caused by the fault or accident including explosion, fire, device damage, decrease of product quality, etc.

(4) Safety precaution. Safety precaution is used to prevent the accident or reduce the loss such as control system, safety instrument system and emergency shutdown system, etc.

\subsection{Definition of relationship between events}

The relationship between events is qualitative in conventional safety analysis. It consists of "positive effect" and "negative effect". Its advantage is simple and easy for modelling. Its disadvantage is that a too simple relationship leads to low accuracy and poor analysis resolution. In order to improve the accuracy and resolution, qualitative trends are used for representing relationship between events. The relationship between events is described by the six basic trend relationships and their combinations. It is shown in Table 1.
Table 1 - Six basic qualitative trend relationships

\begin{tabular}{|c|c|}
\hline $\begin{array}{l}\text { Trend } \\
\text { primitive }\end{array}$ & Definition \\
\hline A & $\begin{array}{c}\operatorname{sign}\left(\frac{\partial \mathrm{e}}{\partial c}\right)=+\operatorname{sign}\left(\frac{\partial^{2} \mathrm{e}}{\partial c^{2}}\right)=- \\
\text { e: influenced event, } c \text { : casual event }\end{array}$ \\
\hline & $\operatorname{sign}\left(\frac{\partial e}{\partial c}\right)=+\operatorname{sign}\left(\frac{\partial^{2} e}{\partial c^{2}}\right)=+$ \\
\hline C & $\operatorname{sign}\left(\frac{\partial \mathrm{e}}{\partial c}\right)=+\operatorname{sign}\left(\frac{\partial^{2} \mathrm{e}}{\partial c^{2}}\right)=0$ \\
\hline & $\operatorname{sign}\left(\frac{\partial \mathrm{e}}{\partial c}\right)=-\operatorname{sign}\left(\frac{\partial^{2} e}{\partial c^{2}}\right)=-$ \\
\hline & $\operatorname{sign}\left(\frac{\partial e}{\partial c}\right)=-\operatorname{sign}\left(\frac{\partial^{2} e}{\partial c^{2}}\right)=+$ \\
\hline & $\operatorname{sign}\left(\frac{\partial \mathrm{e}}{\partial c}\right)=-\operatorname{sign}\left(\frac{\partial^{2} \mathrm{e}}{\partial c^{2}}\right)=0$ \\
\hline
\end{tabular}

The qualitative trend relationship between events can be determined by the signs of first-order derivative and second-order derivative.

\section{Scenario object model based on-line safety analysis}

There are two steps for on-line safety analysis. The first step is to build the new scenario object model. The second step is to do on-line safety analysis once the fault occurs based on the model.

\subsection{Modelling procedure}

The modelling procedure is shown in Fig. 3.

The procedure includes nine steps: (1) Simplifying and modifying the model of the sub-system; (2) Dividing the system into sub-systems; (3) Analysis of energy flows, feed flows, information flows, hazards, dangerous devices, and operation points; (4) Listing key middle events for every sub-system; (5) Listing influence equations to find the middle events that have influence on the key middle events; (6) Determining the relationships between middle events including qualitative relationships and qualitative trend relationships; (7) Adding cause events and consequence events to the model of the sub-system; (8) Simplifying and modifying the model of the sub-system; (9) Connecting all the models of sub-systems to build the entire model of the process. 


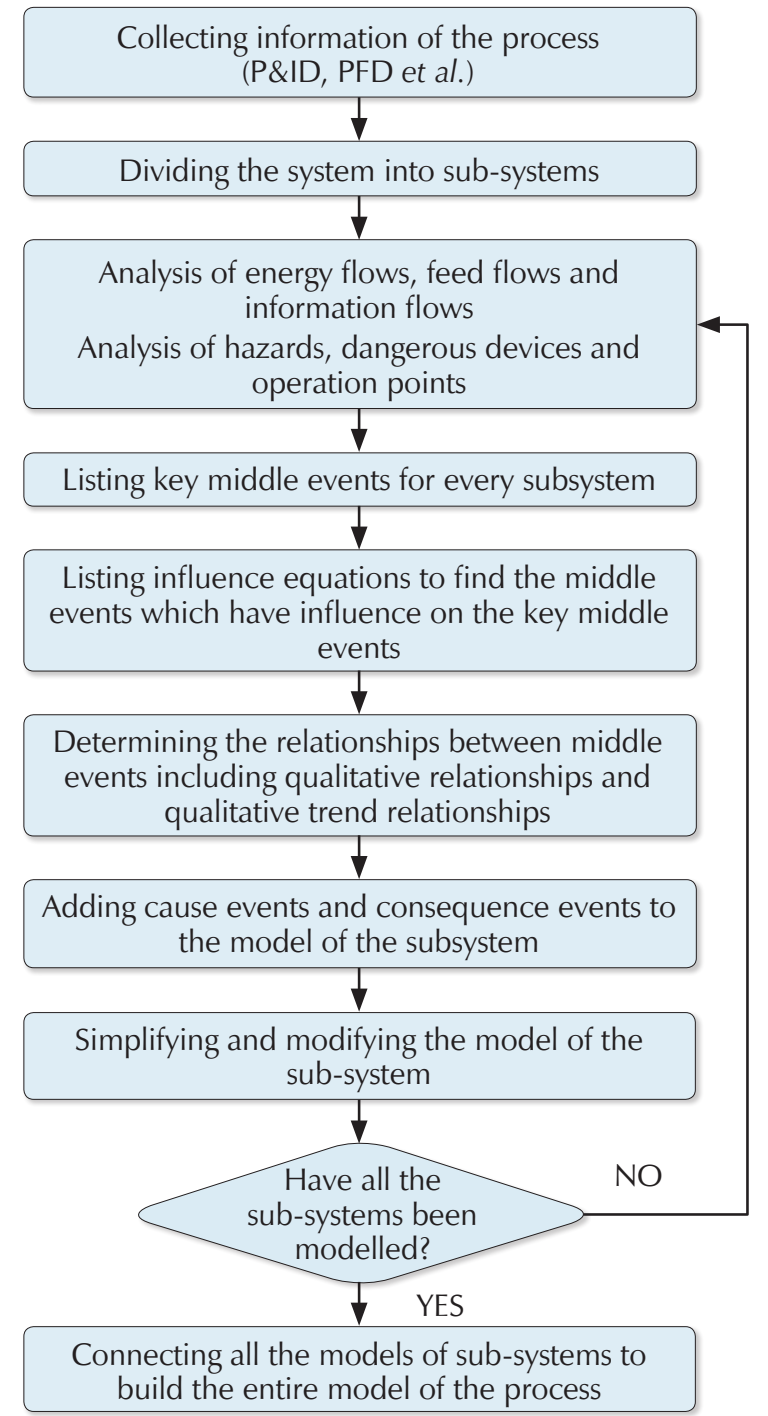

Fig. 3 - Procedure of building on-line scenario object model

In the sixth step, the relationship between events is described in two levels: the first level is qualitative relationship and the second level is qualitative trend relationship. The qualitative trend relationship can be determined by the following rules:

(1) The qualitative trend relationship should be determined according to the rules in Table 1 if the relationship between events can be described by algebraic equation or differential equation. (2) The qualitative trend relationship should be determined by experience if the relationship between events cannot be described by algebraic equation or differential equation.

\subsection{On-line safety analysis}

The procedure of on-line safety analysis is shown in Fig. 4.

On-line safety analysis includes four parts: data monitoring; identifying states of events; inference according to consistent rules; sorting results.

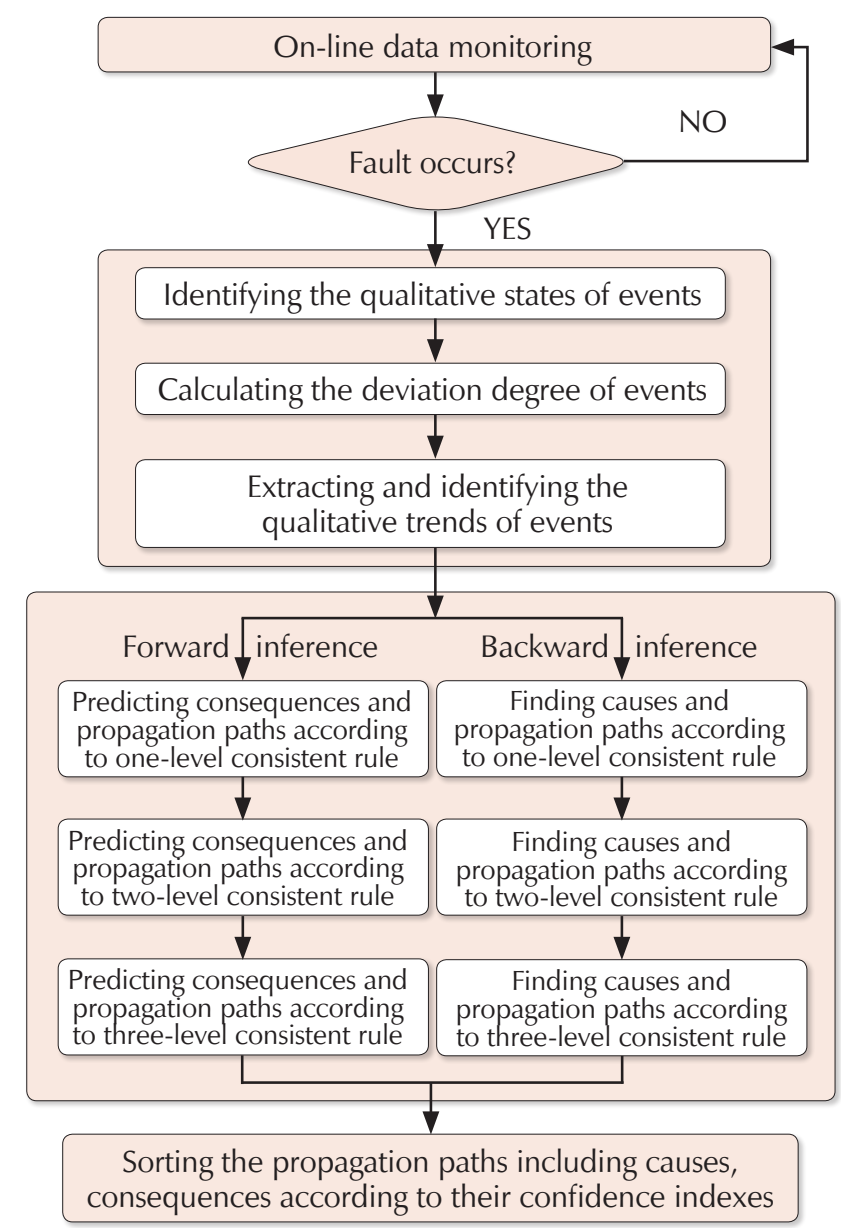

Fig. 4 - Procedure of on-line safety analysis

\subsubsection{On-line data monitoring}

All the variables are monitored in this part. Once a fault occurs, the values of some middle events will be above the high alarming limits or below the low alarming limits. The system is in abnormal state. Then, the states of all events will be calculated or identified, forward and backward inference will be carried out to predict the consequences and find the causes.

\subsubsection{Identification of states of middle events}

The states of the middle event are described in three levels: qualitative state, deviation degree and qualitative trend in the new scenario object model. The accuracy of model can be improved.

\section{(1) Identification of qualitative state}

The qualitative states of events are determined by Eq. (2).

$$
S=\left\{\begin{array}{l}
+, v_{\mathrm{i}}-v_{\text {high }}>0 \\
-, v_{\mathrm{i}}-v_{\text {low }}<0 \\
0, v_{\text {low }} \leq v_{\mathrm{i}} \leq v_{\text {high }}
\end{array}\right.
$$


$S$ is qualitative state, $v_{\mathrm{i}}$ is measured value of a variable, $v_{\text {high }}$ is the high alarming limit, $v_{\text {low }}$ is the low alarming limit. "Positive deviation" is represented by "+". "Negative deviation" is presented by "-". "Normal" is represented by " 0 ".

\section{(2) Calculation of deviation degree}

Deviation degree is calculated by Eq. (1).

\section{(3) Extraction and identification of qualitative trends}

There are two steps to obtain the qualitative trends. The first step is the extraction of trends. The second step is the identification of trends. A qualitative trend analysis method with a sliding window is used for extraction and identification of qualitative trends. ${ }^{20}$

\subsubsection{Forward and backward inference algorithm}

The forward and backward inference will be carried out after the states of middle events have been identified. Forward inference is used to predict the possible consequences and propagation paths. Backward inference is used to find the possible causes and propagation paths.

Forward and backward inferences are both carried out according to consistent rules. The consistent rules are used to determine whether the fault can propagate from one event to another. It is shown in Fig. 5.

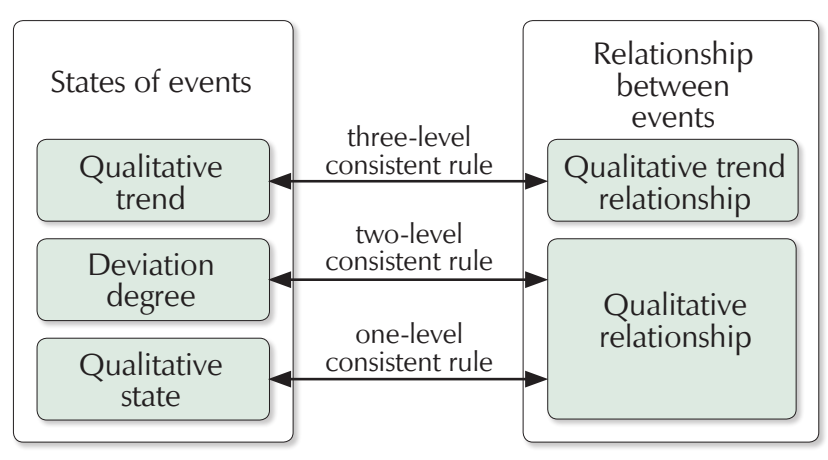

Fig. 5 - Three levels consistent rules

One-level consistent rule is based on qualitative state and qualitative relationship. Two-level consistent rule is based on deviation degree and qualitative state. Three-level consistent rule is based on qualitative trend and qualitative trend relationship. If the three-level consistent rule can be satisfied, the possibility that the fault propagates from one event to another is highest. The targets of forward and backward inference are different; therefore, the consistent rules are different.

\section{(1) Consistent rule of forward inference}

Forward inference is used to predict the states of events and consequences. For example, event $E_{B}$ is influenced by event $E_{A}$. If $E_{A}$ is in abnormal condition, the forward inference is carried out from $E_{\mathrm{A}}$. The consistent rule is as follows:

\section{(1) One-level consistent rule}

The qualitative state of $E_{\mathrm{B}}$ is the product of the qualitative state of $E_{\mathrm{A}}$ and the qualitative relationship between $E_{\mathrm{A}}$ and $E_{\mathrm{B}}$ when $E_{\mathrm{B}}$ is only influenced by $E_{\mathrm{A}}$. It is shown in Eq. (3).

$$
S_{\mathrm{B}}=S_{\mathrm{A}} \cdot R_{\mathrm{AB}}
$$

$S_{B}$ is the qualitative state of $E_{B}, S_{A}$ is the qualitative state of $E_{\mathrm{A}}, R_{\mathrm{AB}}$ is the qualitative relationship between $E_{\mathrm{A}}$ and $E_{\mathrm{B}}$.

The qualitative state of $E_{\mathrm{B}}$ is the sum of the influences of all the events when there are other events that influence $E_{\mathrm{B}}$ besides $E_{\mathrm{A}}$. It is shown in Eq. (4).

$$
S_{\mathrm{B}}=\sum_{i=1}^{N} S_{i}
$$

$S_{i}$ is the qualitative state of $E_{\mathrm{B}}$ influenced by event $i . N$ is the number of events which will influence $E_{\mathrm{B}}$. The state of $E_{\mathrm{B}}$ will be "?" if the influences of events to $E_{\mathrm{B}}$ are different.

\section{(2) Two-level consistent rule}

The deviation degree of $E_{\mathrm{B}}$ is the product of the deviation degree of $E_{\mathrm{A}}$ and the qualitative relationship between $E_{\mathrm{A}}$ and $E_{\mathrm{B}}$ when $E_{\mathrm{B}}$ is only influenced by $E_{\mathrm{A}}$. It is shown in Eq. (5).

$$
\text { Deviation }_{\mathrm{B}}=\text { Deviation }_{\mathrm{A}} \cdot R_{\mathrm{AB}}
$$

Deviation $_{\mathrm{B}}$ is the deviation degree of $E_{\mathrm{B}}$, Deviation Dis $_{\mathrm{A}}$ is the deviation degree of $E_{\mathrm{A}}, R_{\mathrm{AB}}$ is the qualitative relationship between $E_{\mathrm{A}}$ and $E_{\mathrm{B}}$.

The deviation degree of $E_{\mathrm{B}}$ is the sum of the influences of all the events when there are other events that influence $E_{\mathrm{B}}$ besides $E_{\mathrm{A}}$. It is shown in Eq. (6).

$$
\text { Deviation }_{\mathrm{B}}=\sum_{i=1}^{N} \text { Deviation }_{i}
$$

Deviation $_{i}$ is the deviation degree of $E_{\mathrm{B}}$ influenced by event $i$.

\section{(3) Three-level consistent rule}

The qualitative trend of $E_{\mathrm{B}}$ is determined by the qualitative trend of $E_{A}$ and the qualitative trend relationship between $E_{\mathrm{A}}$ and $E_{\mathrm{B}}$ when $E_{\mathrm{B}}$ is only influenced by $E_{\mathrm{A}}$. It is shown in Table 2 . 
Table 2 - Three-level consistent rule for forward inference

\begin{tabular}{c|c|c|c|c|c|c|}
\hline $\begin{array}{l}\text { Qualitative trend relationship } \\
\text { between } E_{\mathrm{A}} \text { and } E_{\mathrm{B}} \\
\text { Qualitative trend of } E_{\mathrm{A}}\end{array}$ & $\mathrm{A}$ & $\mathrm{B}$ & $\mathrm{C}$ & $\mathrm{D}$ & $\mathrm{E}$ & $\mathrm{F}$ \\
\hline A & A & C & A & F & E & E \\
B & C & B & B & D & F & D \\
C & A & B & C & D & E & F \\
D & F & D & D & B & C & B \\
E & E & F & E & C & A & A \\
F & E & D & F & B & A & C \\
\hline
\end{tabular}

The qualitative trend of $E_{\mathrm{B}}$ is the superposition of the influences of all the events when there are other events that influence $E_{\mathrm{B}}$ besides $E_{\mathrm{A}}$. For example, if $E_{\mathrm{B}}$ is influenced by $E_{\mathrm{A}}$ and $E_{\mathrm{C}}$. The qualitative trend of $E_{\mathrm{B}}$ is the superposition of the influences of $E_{\mathrm{A}}$ and $E_{\mathrm{C}}$. The rule is shown in Table 3.

Table 3 - Superposition rule of qualitative trends for forward inference

\begin{tabular}{|c|c|c|c|c|c|c|c|}
\hline $\begin{array}{l}\text { Qualitative trend of } E_{\mathrm{B}} \\
\text { influenced by } E_{\mathrm{A}} \\
\text { Qualitative trend of } E_{\mathrm{B}} \\
\text { influenced by } E_{\mathrm{C}}\end{array}$ & $A$ & $B$ & C & $\mathrm{D}$ & $\mathrm{E}$ & $\mathrm{F}$ & ? \\
\hline$A$ & $A$ & C & A & ? & $?$ & ? & ? \\
\hline B & C & B & B & ? & $?$ & $?$ & ? \\
\hline C & $A$ & B & C & $?$ & $?$ & $?$ & ? \\
\hline $\mathrm{D}$ & $?$ & $?$ & $?$ & $\mathrm{D}$ & $\mathrm{F}$ & $\mathrm{D}$ & ? \\
\hline $\mathrm{E}$ & $?$ & $?$ & $?$ & $F$ & $E$ & $E$ & ? \\
\hline $\mathrm{F}$ & $?$ & ? & $?$ & $\mathrm{D}$ & $\mathrm{E}$ & $\mathrm{F}$ & ? \\
\hline$?$ & $?$ & ? & $?$ & $?$ & $?$ & ? & ? \\
\hline
\end{tabular}

The state "?" represents that the state of $E_{\mathrm{B}}$ is uncertain. The rule can also be used for superposition of more than two events that influence the state of $E_{\mathrm{B}}$ The possible propagation paths (consistent paths) and consequences can be predicted according to the above consistent rules.

\section{(2) Consistent rule of backward inference}

Backward inference is used to find possible fault causes and propagation paths. For example, event $E_{\mathrm{B}}$ is influenced by event $E_{\mathrm{A}}$. If $E_{\mathrm{B}}$ is in abnormal condition, the backward inference is carried out from $E_{\mathrm{B}}$. The consistent rule is as follows:

\section{(1) One-level consistent rule}

The arc from $E_{\mathrm{A}}$ to $E_{\mathrm{B}}$ is consistent if the product of the qualitative state of $E_{\mathrm{B}}$ and $E_{\mathrm{A}}$ and the qualitative relation between $E_{\mathrm{A}}$ and $E_{\mathrm{B}}$ is positive. It is shown in Eq. (7).

$$
S_{\mathrm{B}} \cdot S_{\mathrm{A}} \cdot R_{\mathrm{AB}}=+
$$

It is consistent if the Eq. (7) can be satisfied. If the formula cannot be satisfied, there will be two conditions: a) if $E_{\mathrm{A}}$ is influenced by one event, the $\operatorname{arc}$ from $E_{\mathrm{A}}$ to $E_{\mathrm{B}}$ is not consistent; b) if $E_{A}$ is influenced by more than one event, the $\operatorname{arc}$ from $E_{\mathrm{A}}$ to $E_{\mathrm{B}}$ is supposed to be consistent. Backward inference continues.

\section{(2) Two-level consistent rule}

The arc from $E_{\mathrm{A}}$ to $E_{\mathrm{B}}$ is consistent if the sign of product of the deviation degree of $E_{\mathrm{B}}$ and $E_{\mathrm{A}}$ and the qualitative relation between $E_{\mathrm{A}}$ and $E_{\mathrm{B}}$ is positive. It is shown in $\mathrm{Eq}$. (8).

$$
\operatorname{sign}\left(\text { Deviation }_{\mathrm{B}} \cdot \text { Deviation }_{\mathrm{A}} \cdot R_{\mathrm{AB}}\right)=+
$$

It is consistent if the Eq. (8) can be satisfied. If the formula cannot be satisfied, there will be two conditions: a) if $E_{\mathrm{A}}$ is influenced by one event, the arc from $E_{\mathrm{A}}$ to $E_{\mathrm{B}}$ is not consistent; b) if $E_{\mathrm{A}}$ is influenced by more than one event, the $\operatorname{arc}$ from $E_{\mathrm{A}}$ to $E_{\mathrm{B}}$ is supposed to be consistent. Backward inference continues.

\section{(3) Three-level consistent rule}

Whether the arc from $E_{\mathrm{A}}$ to $E_{\mathrm{B}}$ is consistent is determined by the qualitative trend of $E_{A}$ and $E_{B}$ and the qualitative relationship between $E_{\mathrm{A}}$ and $E_{\mathrm{B}}$. The qualitative trends " $\mathrm{A}$ ", " $B$ " and " $C$ " are called "Increase". The qualitative trends "D", " $E$ " and " $F$ " are called "Decrease". The arc from $E_{\mathrm{A}}$ to $E_{\mathrm{B}}$ is consistent if one of the two conditions can be satisfied: The qualitative trend of $E_{\mathrm{A}}$ and $E_{\mathrm{B}}$ are the same ("Increase" or "Decrease") and the relationship is "Increase". The qualitative trends of $E_{\mathrm{A}}$ and $E_{\mathrm{B}}$ are different (one is "Increase" and the other is "Decrease") and the relationship is "Decrease". If the arc from $E_{\mathrm{A}}$ to $E_{\mathrm{B}}$ is not consistent according to the above rule, there will be two conditions: a) if $E_{\mathrm{A}}$ is influenced by one event, the arc from $E_{\mathrm{A}}$ to $E_{\mathrm{B}}$ is not consistent; b) if $E_{A}$ is influenced by more than one event, the arc from $E_{\mathrm{A}}$ to $E_{\mathrm{B}}$ is supposed to be consistent. Backward inference continues. The possible propagation paths (consistent paths) and causes can be found according to above consistent rules.

\subsubsection{Sorting results}

The possible causes, consequences and consistent paths (propagation paths) have been found by forward and backward inference. All the paths will be sorted according to 
confidence indexes to improve the analysis resolution. Confidence index of a consistent path represents the possibility that the fault propagates along the path. The higher the index is, the higher the possibility that the fault propagates along the path. The confidence index is calculated by Eq. (9).

$$
C_{\text {path }}=\frac{1}{N} \sum_{i=1}^{N} C_{\text {arci }}
$$

$C_{\text {path }}$ is the confidence index of the path. $N$ is the number of consistent arcs in the path. $C_{\text {arci }}$ is the confidence index of the ith consistent arc. The confidence index of every consistent arc is decided by its consistent level: (1) if the three-level consistent rule can be satisfied, the confidence index of consistent arc is 3; (2) if the two-level consistent rule can be satisfied, the confidence index of consistent arc is 2 ; (3) if only the one-level consistent rule can be satisfied, the confidence index of consistent arc is 1.

\section{Case study}

The scenario object model based on-line safety analysis is used for a reactor process. The pipe \& instrument diagram is shown in Fig. 6.

The description of devices and variables in the process is shown in Table 4.

The process is as follows: materials $A$ and $B$ enter into tank V101, and then the mix material including $A$ and $B$ enter into the reactor R101 through the heat exchanger E101. The mix material will exchange heat with water from the jacket of the reactor. The heat exchanger is used to preheat the mix material. The catalyser enters into the reactor after the mix material including $A$ and $B$ enter into the reactor. In the reactor, $A$ and $B$ react to produce $D$ and $E$ in the presence of the catalyser. The reaction is exothermic so cold water is used to control the reaction temperature. The cold water enters into the jacket of the reactor. Part of the water is sent to utilities and the remainder is sent to heat exchanger to preheat the mix material. The bottom material including $A, B, D$, and $E$ of the reactor enter into the flash tank V102 to separate the products D, E, and A, which are not entirely consumed in the reactor and will be separated into the top of the flash tank for distillation unit. The real product enters into the next unit from the bottom of the flash tank.

The on-line scenario object model of the above process is built using the software called SDGHAZOP v3.0., developed by us, and the latest version is 3.0. Scenario object model including deviation degree and qualitative trend is added to the software. The model is shown in Fig. 7.

The " $R$ " rectangle is the cause event where the fault causes are stored. The " $\mathrm{C}$ " rectangle is the consequence event where the consequences are stored. The circle is middle event. The relationship between middle events is described in two ways: (1) Qualitative relationship. Real line means positive effect and dotted line means negative effect. (2) Qualitative trend relationship. The relationship between events is described by qualitative trends such as A, B, C, D, $E$, and $F$, shown in Table 1 .

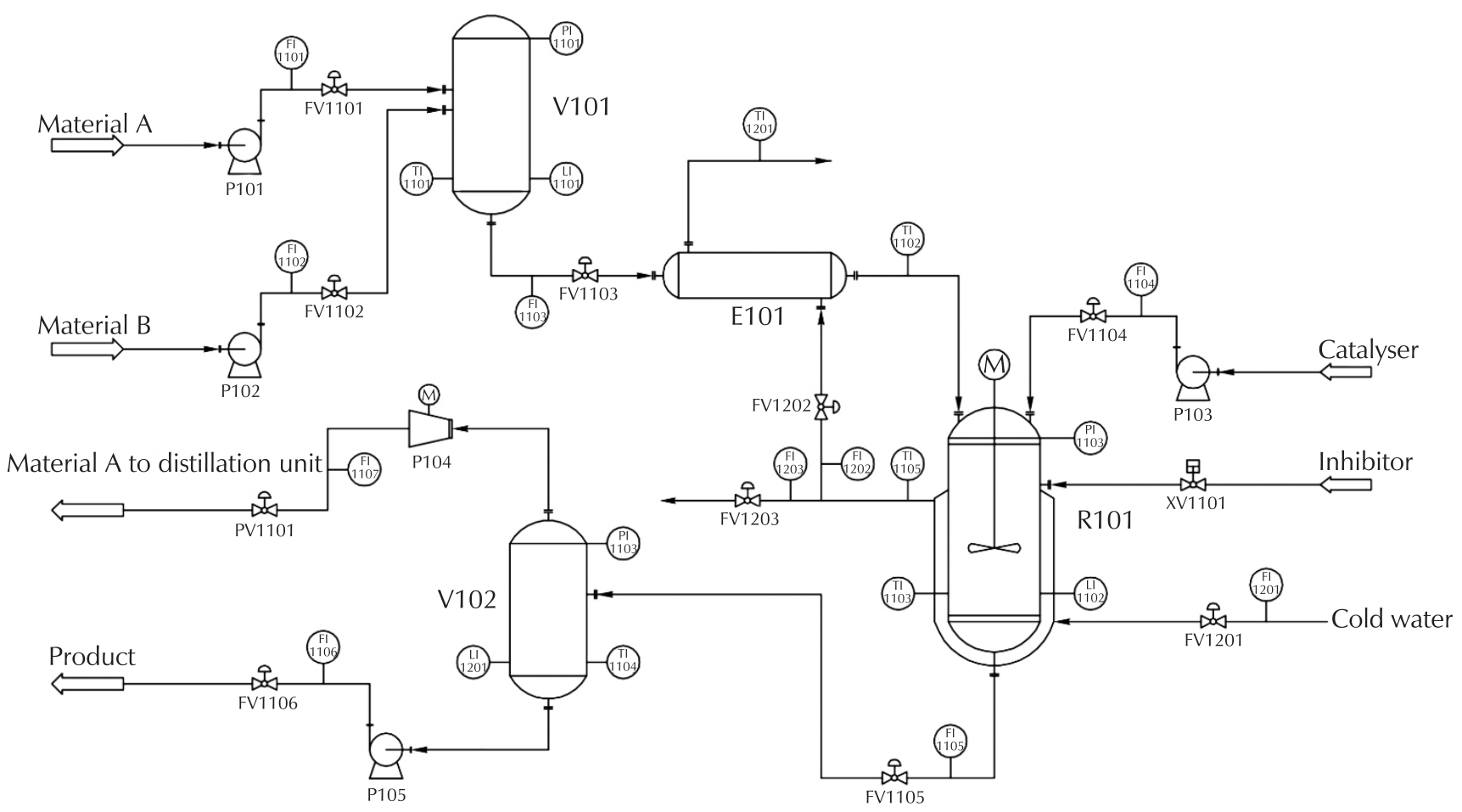

Fig. 6 - Pipe \& instrument diagram of reactor process 
Table 4 - Description of devices and variables

\begin{tabular}{|c|c|c|c|c|c|}
\hline Name & Description & Unit & Name & Description & Unit \\
\hline P101 & pump for material A & & Fl1103 & material $\mathrm{A}$ and $\mathrm{B}$ flow & $\mathrm{kg} \mathrm{s}^{-1}$ \\
\hline P102 & pump for material B & & FI1104 & catalyser flow & $\mathrm{kg} \mathrm{s}^{-1}$ \\
\hline P103 & pump for catalyser & & Fl1105 & bottom of the reactor flow & $\mathrm{kg} \mathrm{s}^{-1}$ \\
\hline P104 & pump for material A to distillation unit & & FI1107 & V102 Top flow & $\mathrm{kg} \mathrm{s}^{-1}$ \\
\hline P105 & pump for product & & FI1201 & cold water flow & $\mathrm{kg} \mathrm{s}^{-1}$ \\
\hline V101 & tank for mix materials & & FI1202 & water to heat exchanger flow & $\mathrm{kg} \mathrm{s}^{-1}$ \\
\hline E101 & heat exchanger & & Fl1203 & water to utilities flow & $\mathrm{kg} \mathrm{s}^{-1}$ \\
\hline R101 & reactor & & Fl1106 & product flow & $\mathrm{kg} \mathrm{s}^{-1}$ \\
\hline V102 & flash tank & & LI1101 & V101 level & $\%$ \\
\hline FV1101 & valve of material $\mathrm{A}$ flow & $\%$ & LI1102 & R101 level & $\%$ \\
\hline FV1102 & valve of material $\mathrm{B}$ flow & $\%$ & LI1201 & V102 level & $\%$ \\
\hline FV1103 & valve of material $A$ and $B$ flow & $\%$ & TI1101 & V101 temperature & ${ }^{\circ} \mathrm{C}$ \\
\hline FV1104 & valve of catalyser flow & $\%$ & TI1102 & $\begin{array}{l}\text { mix material temperature from } \\
\text { heat exchanger to reactor }\end{array}$ & ${ }^{\circ} \mathrm{C}$ \\
\hline FV1201 & valve of water flow & $\%$ & TI1103 & R101 temperature & ${ }^{\circ} \mathrm{C}$ \\
\hline FV1202 & valve of water to heat exchanger flow & $\%$ & TI1104 & V102 temperature & ${ }^{\circ} \mathrm{C}$ \\
\hline FV1203 & valve of water to utilities flow & $\%$ & TI1105 & water temperature in the jacket of the reactor & ${ }^{\circ} \mathrm{C}$ \\
\hline XV1101 & valve of inhibitor flow & $\%$ & TI1201 & water temperature after the heat exchanger & ${ }^{\circ} \mathrm{C}$ \\
\hline FV1105 & valve of bottom of the reactor flow & $\%$ & PI1101 & V101 pressure & $\mathrm{kPa}$ \\
\hline FV1106 & valve of product flow & $\%$ & PI1102 & R101 pressure & $\mathrm{kPa}$ \\
\hline PV1101 & valve of material $A$ to distillation unit flow & $\%$ & PI1103 & V102 pressure & $\mathrm{kPa}$ \\
\hline Fl1102 & material B flow & $\mathrm{kg} \mathrm{s}^{-1}$ & & & \\
\hline
\end{tabular}

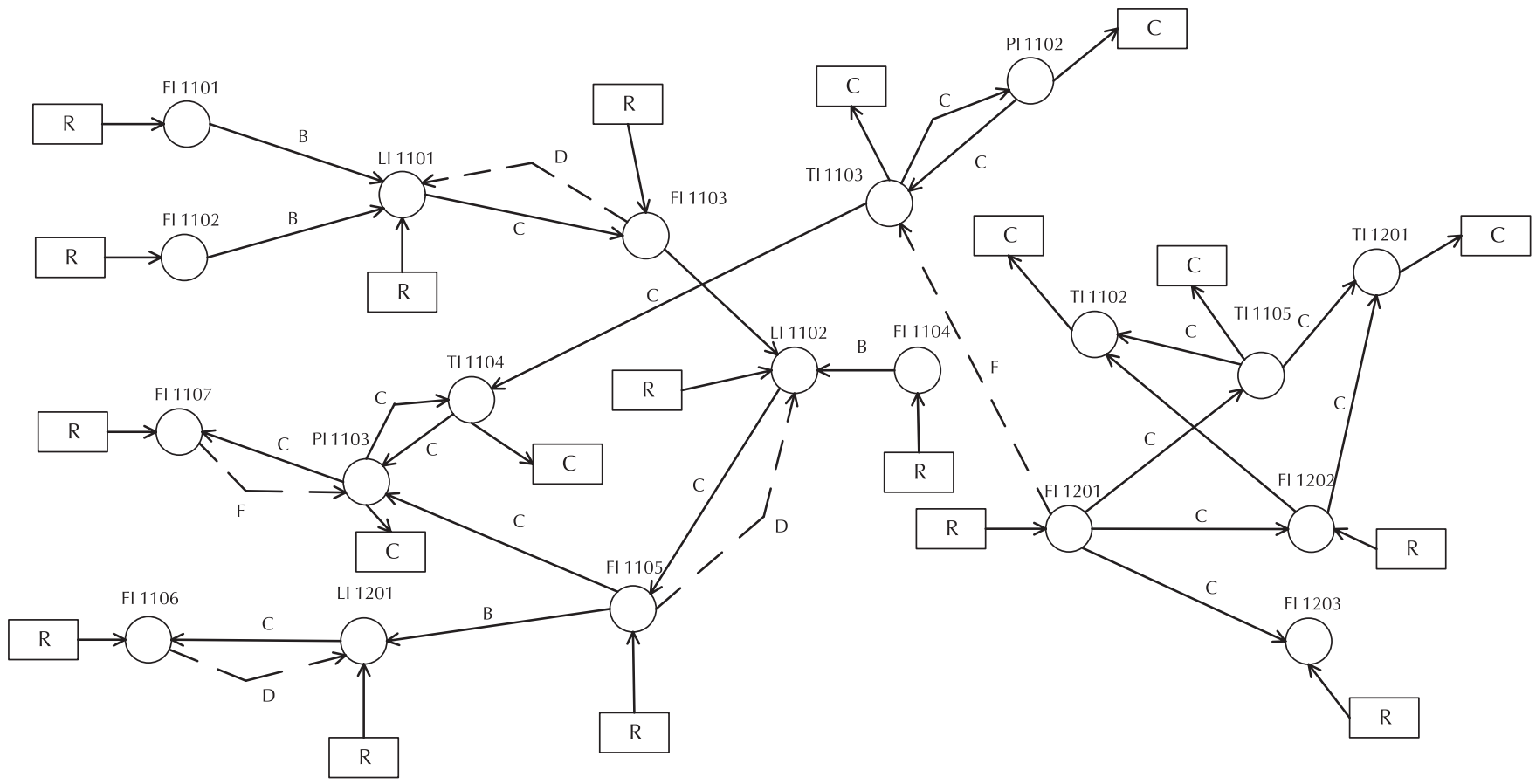

Fig. 7 - On-line scenario object model of reactor process 
Take the cold water flow decrease for example. The causes of flow decrease include controller fault, value fault, worker wrong operation, etc. When the fault occurs, the reactor temperature (TI1103) increases. Then the on-line safety analysis is carried out.

The qualitative states of variables are determined by Eq. (2). For example, the qualitative state of TI1103 is "+" because the value of $\mathrm{TI} 1103$ is $96{ }^{\circ} \mathrm{C}$ and it is higher than its high limit $95{ }^{\circ} \mathrm{C}$. The deviation degrees are then calculated by Eq. (1). For example, the value of TI1103 is $96{ }^{\circ} \mathrm{C}$. The set point is $94{ }^{\circ} \mathrm{C}$. The maximum value is $96.5{ }^{\circ} \mathrm{C}$. Therefore, the deviation degree $P$ is:

$$
P=\frac{96-94}{96.5-94}=0.8
$$

The qualitative trends are also extracted and identified using a qualitative trend analysis method with a sliding window. ${ }^{20}$ The qualitative trend of TI1103 is B.

According to the states of variables, the possible consequences are predicted by forward inference and the possible causes are found by backward inference. The result is as follows:

Consistent paths found by forward inference:

$\mathrm{TI} 1103(+/ 0.8 / \Omega) \rightarrow$ Consequences (reaction rate and quality of product will be affected; device will be damaged); TI1103(+/0.8/ ) $\rightarrow$ PI1102(+/0.8/ ) $\rightarrow$ Consequences (reactor will explode); TI1103(+/0.8/ $) \rightarrow$ $\mathrm{TI1104}(+/ 0.8 / \Omega) \rightarrow$ Consequences (quality of product will be affected; device will be damaged); TI1103(+/0.8/ ) $\rightarrow \mathrm{TI} 1104(+/ 0.8 / \Omega) \rightarrow \mathrm{Pl} 103(+/ 0.8 / \Omega) \rightarrow$ Consequences (quality of product will be affected; flash tank will explode).

"+" represents the current state ("positive deviation"), " 0.8 " represents the deviation degree calculated, J represents the qualitative trend. The possible consequences, paths, and trends are revealed by the four paths.

It should be pointed out that forward inference aims to predict the possible consequences from the abnormal variable. Therefore, the states of the other variables including qualitative states, deviation degrees and qualitative trends are all predicted according to consistent rule of forward inference. In this case, for example, the deviation degree of TI1103 is calculated by Eq. (1) and the other deviation degrees are predicted according to consistent rule of forward inference.

Consistent path found by backward inference is as follows:

$\mathrm{TI1103}(+/ 0.8 / \Lambda) \leftarrow \mathrm{FI} 1201(+/ 1.0 / \Omega) \longleftarrow$ Reasons(controller fault, value fault, and worker wrong operation). The path is the real path along which the fault propagates. The process of the fault occurring and its propagation are revealed by the path. Backward inference aims to find the possible causes from the abnormal variable. So the states of variables in the path are calculated according to Eq. (1), Eq. (2) and the qualitative trend analysis method with a sliding window. ${ }^{20}$

The advantages of on-line safety analysis are shown by the example. It can not only find the consequences and fault causes in time, but can also predict the development by deviation degrees and qualitative trends. The example is quite simple. More complex objects, conditions and multiple faults occurring will lead to many results. In this situation, the advantages of on-line safety analysis can show its advantages including consequences prediction and fault causes location, especially high diagnosis resolution (sorting by confidence index).

\section{Conclusion}

It is essential that on-line safety analysis can be used for chemical processes. However, the conventional safety analysis is carried out off-line and most of them are qualitative. For this problem, scenario object model based on-line safety analysis was proposed for chemical processes. The advantages of the method are as follows:

(1) The method is based on the improved scenario object model. The transfer, reuse and sharing of safety information can be satisfied and the method can be used on-line.

(2) Once a fault or abnormal event occurs, on-line safety analysis is carried out to find causes and predict the possible consequences supplying the instruction for fault treatment.

(3) Some semi-quantitative information such as deviation degree, qualitative trend, etc., have been added to the scenario object model to improve the accuracy of the model. Based on the model, on-line safety analysis is carried out and the diagnosis resolution can be improved. It is helpful for fault location and treatment in time.

How to improve the model according to its application is the next research target.

\section{ACKNOWLEDGEMENTS}

This work is supported by National Natural Science Foundation of China (Grant No: 61703026)

\section{List of abbreviations and symbols}

HAZOP - Hazard and Operability Analysis

SDG - Signed Directed Graph

SOM - Scenario Object Model

$\mathrm{C}_{\text {path }}$ - confidence index of the path

E - event

$P \quad-$ deviation degree

$R \quad$ - qualitative relationship between events

$S \quad$ - qualitative state

$\checkmark \quad-$ measured value

\section{References}

\section{Literatura}

1. C. G. Wu, Hazard and operability analysis basic and application, Beijing, China Petrochemical Press, 2012, pp. 1-3.

2. Y. Li, L. Xiong, H. F. Deng, Application of SIL evaluation and HAZOP analysis technology in safety assessment of offshore 
platform, J. Saf. Sci. Technol. 13 (8) (2013) 119-124, url: http://caod.oriprobe.com/articles/39395822/sil_ping gu ji hazop_fen_xi_ji_shu_zai_hai_yang_pi.htm.

3. C. X. Xiao, Q. Chen, Application of HAZOP in safety risk analysis of mine ventilation system, J. Saf. Sci. Technol. 13 (11) (2013) 97-102, url: http://caod.oriprobe.com/articles/41185545/Application_of_HAZOP_in_safety_risk analysis_of_mine_ventilation_syste.htm.

4. S. Zhou, F. Q. Shi, J. Chai, HAZOP-based safety risk analysis technology for railway operation, China Saf. Sci. J. 24 (8) (2014) 92-96, url: http://caod.oriprobe.com/articles/43008138/HAZOP_based_safety_risk_analysis_technology_for_railway_operation.htm.

5. Y. L. Zhang, W. T. Zhang, B. K. Zhang, Automatic HAZOP analysis method for unsteady operation in chemical based on qualitative simulation and inference, Chin. J. Chem. Eng. 23 (12) (2015) 2065-2074, doi: https://doi.org/10.1016/j. cjche.2015.10.004.

6. F. F. Huo, S. Z. Yao, H. B. Tao, System safety requirement based on misuse case, Comput. Eng. Des. 37 (10) (2016) 26132616, url: http://caod.oriprobe.com/articles/49473844/System_safety_requirement_based_on_misuse_case.htm.

7. Y. Gui, M. G. Zhang, Q. Yu, Study on HAZZOP quantitative analysis of benzene nitrification based on simulation, Ind. Saf. Environ. Prot. 42 (10) (2016) 44-46, url: http://caod. oriprobe.com/articles/49484030/Study_on_HAZOP_Quantitative_Analysis_of_Benzene_Nitrification_Based_on.htm.

8. ISO 10303-11, Industrial automation systems and integration - Product data representation and exchange Part 11: Description methods: The EXPRESS language reference manual, 1994.

9. ISO 15926-2, Integration of lifecycle data for process plant including oil and gas production facilities Part 2: Data model, 2003.

10. R. Batres, T. Suzuki, Y. Shimada, T. Fuchino, A graphical approach for hazard identification, $18^{\text {th }}$ European Symposium on Computer Aided Process Engineering, 2008.

11. K. Kuraoka, R. Batres, An Ontological Approach to Represent HAZOP Information, Process Systems Engineering Laboratory, Tokyo Institute of Technology, 2003.
12. B. H. Lee, Using FMEA models and ontologies to build diagnostic models, Artif. Intell. Eng. Des. Anal. Manuf. 15 (4) (2001) 281-293, doi: https://doi.org/10.1017/ S089006040115403X.

13. C. G. $W u, X . X u, Y$. L. Na, Standardized information for process hazard analysis based on ontology, CIESC J. 63 (5) (2012) 1485-1491, url: http://caod.oriprobe.com/articles/29457787/Standardized information for_process hazard_analysis_based_on_ontōogy.htm.

14. B. K. Zhang, X. Xu, Y. L. Na, Hazard analysis and application based on graphical scenario object model, CIESC J. 64 (7) (2013) 2511-2519, url: http://caod.oriprobe.com/articles/37989824/ji_yu_tu_xing_hua_ju_qing_dui_xiang_mo_ xing_de_an_htm.

15. C. G. Wu, X. Xu, B. K. Zhang, Y. L. Na, Domain ontology for scenario-based hazard evaluation, Saf. Sci. 60 (2013) 21-34, doi: https://doi.org/10.1016/j.ssci.2013.06.003.

16. J. $X u, Y$. Liu, Y. Zhang, The research and development of emergency guidance system based on HAZOP, Saf. Health Environ. 16 (1) (2016) 14-17, url: http://caod.oriprobe.com/ articles/47494381/The Research and Development of Emergency_Guidance_System_Basēdon__HAZ.htm.

17. M. R. Maurya, R. Rengaswamy, V. Venkatasubramanian, A signed directed graph-based systematic framework for steady-state malfunction diagnosis inside control loop, Chem. Eng. Sci. 61 (6) (2006) 1790-1810, doi: https://doi. org/10.1016/j.ces.2005.10.023.

18. T. Xia, B. K. Zhang, C. G. Wu, SDG fault diagnosis simulation system for petrochemical process, J. Syst. Simulation. 15 (10) (2003) 1377-1380, url: http://caod.oriprobe.com/ articles/6656717/SDG Fault Diagnosis Simulation System_for_Petrochemical_Process.htm.

19. R. Srinivasan, M. S. Qian, Online fault diagnosis and state identification during process transitions using dynamic locus analysis, Chem. Eng. Sci. 61 (18) (2006) 6109-613, doi: https://doi.org/10.1016/j.ces.2006.05.037.

20. D. Gao, X. Ma, X. Xu, The method and application of qualitative trend analysis with a sliding window, Appl. Res. Comp. 31 (5) (2014) 1441-1444, url: http://caod.oriprobe.com/ articles/41544162/Method_and_application_of_qualitative trend analysis with sliding wind. witm.

\title{
SAŽETAK
}

\section{Sigurnosna on-line analiza kemijskog procesa temeljena na scenarijskom objektnom modelu

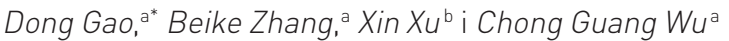

\begin{abstract}
HAZOP (analiza opasnosti i operativnosti) metoda je sigurnosne analize koja se primjenjuje u kemijskim procesima. Konvencionalne metode za analizu sigurnosti mogu biti ljudske i računalne. Sve su to kvalitativne i off-line analize, a sigurnosnu on-line analizu teško je provesti. Za kemijske procese predložena je sigurnosna on-line analiza temeljena na scenarijskom objektnom modelu. Scenarijski objektni model izrađen je ontološki, čime se sigurnosne informacije mogu učinkovito prenijeti, ponovno upotrijebiti i dijeliti. Stupanj devijacije i kvalitativni trend pridodani su modelu. Na temelju modela i novog algoritma zaključivanja sigurnosna se on-line analiza može implementirati u kemijske procese. Kada se dogodi pogreška ili abnormalni događaj, mogu se pratiti uzroci i predvidjeti posljedice. Istodobno se provodi polukvantitativna sigurnosna analiza. Rješenje je moguće poboljšati i time omogućiti operaterima pravodobno i učinkovito rješavanje problema. Metoda je primijenjena za sigurnosnu analizu reaktorskog procesa te je dokazana njezina učinkovitost.
\end{abstract}

Ključne riječi

Scenarijski objektni model, on-line, analiza opasnosti, HAZOP, kvalitativni trend

${ }^{a}$ College of Information Science and

Technology, Beijing University of Chemical

Technology, Peking, Kina

${ }^{\mathrm{b}}$ Beijing Digital Process Technology Co. Ltd., Peking, Kina
Izvorni znanstveni rad

Prispjelo 25. srpnja 2017.

Prihvaćeno 26. listopada 2017. 